\title{
AS DIFICULDADES PARA INSERÇÃO NO MERCADO DE TRABALHO - ANÁLISE DAS TRAJETÓRIAS DE ALUNOS DA EJA EM UMA ESCOLA DE PERIFERIA
}

\section{ARTIGO ORIGINAL}

SANTO, Adriana Rocha Furtunato do Espírito ${ }^{1}$

RAGGI, Désirée Gonçalves ${ }^{2}$

SANTO, Adriana Rocha Furtunato do Espírito. RAGGI, Désirée Gonçalves. As dificuldades para inserção no Mercado de Trabalho - Análise das trajetórias de alunos da EJA em uma escola de periferia. Revista Científica Multidisciplinar Núcleo do Conhecimento. Ano 05, Ed. 04, Vol. 06, pp. 151-181. Abril de 2020. ISSN: 2448-0959, Link de

acesso: https://www.nucleodoconhecimento.com.br/educacao/trajetorias-de-alunos

\section{RESUMO}

O presente artigo se propõe apresentar quais as dificuldades encontradas pelos alunos da Educação de Jovens e Adultos (EJA) em se colocarem no mercado de trabalho, revelando porque, após tantas oportunidades, resolveram estudar novamente e quais as dificuldades que estão encontrando, depois de longo tempo fora da escola. A pesquisa descreve as trajetórias percorridas pelos alunos da EJA para encontrar uma vaga no mercado de trabalho buscando investigar as dificuldades enfrentadas por estes. O público da Educação de Jovens e Adultos (EJA) constituise, majoritariamente, por indivíduos que tiveram passagens fracassadas pela escola, sendo excluídos do sistema regular. A arguição dispõe de 30 jovens e adultos

\footnotetext{
${ }^{1}$ Mestre em Ciência, Tecnologia e Educação pela Faculdade Vale do Cricaré - São Mateus - ES. Professora da rede pública estadual em Cariacica - ES.

2 Doutora em Ciências da Educação pela Faculdade UNINORTE - Paraguai. Professora na Faculdade Vale do Cricaré - São Mateus - ES.
} 
entrevistados, do $2^{\circ}$ e $3^{\circ}$ anos da EJA, que pertencem a regiões periféricas de extrema pobreza e desigualdade social. A metodologia é classificada como estudo de caso descritivo, sendo 15 (quinze) do $2^{\circ}$ ano e 15 (quinze) do $3^{\circ}$ ano do Ensino Médio da EJA. Dessa amostra, foram escolhidos 10 (dez) sujeitos e analisadas as respectivas trajetórias, tanto no contexto de vida, quanto os percalços na busca do emprego. Dentre os motivos que os levaram a cursar EJA, constatou-se o desejo de concluir uma formação superior, na busca de qualificação profissional. Concluiu-se que os fatores mais limitadores são a falta de escolarização, avanço da idade e as poucas oportunidades na oferta de emprego devido à ausência de qualificação.

Palavras-chave: Educação de Jovens e Adultos, Mercado de Trabalho, emprego.

\section{INTRODUÇÃO}

O contato com a Educação de Jovens e Adultos (EJA) levou-me a refletir sobre as oportunidades que eles ganham e perdem ao almejar uma condição mais digna para sua sobrevivência, visto que, no Brasil, a EJA sempre foi marcada por movimentos ou iniciativas individuais de grupos, órgãos públicos e privados ou pesquisadores decididos a enfrentar o problema da existência de uma lacuna social representada pelo enorme contingente da população que não teve a oportunidade de frequentar a escola de ensino básico (Fundamental e Médio). Os dados estatísticos extraídos do Censo revelaram que, no ano de 2018, foram matriculados, na EJA, na rede municipal de Cariacica, 2.949 alunos no Ensino Fundamental e sem oferta do Ensino Médio. Na rede estadual de Cariacica havia 544 alunos no Ensino Fundamental e 3.305 no Ensino Médio, nesta modalidade.

A história desses movimentos revela descontinuidades, contradições e desafios permanentes em face das diferentes experiências e orientações de suas práticas. Constituem tais iniciativas, matrizes pelas quais novas experiências vão se constituindo. A essência dos novos e dos antigos movimentos, nessa direção, possui um ponto de convergência: o compromisso político diante da injustiça social. 
A inserção do jovem da EJA no mercado de trabalho depende da retomada relativa da situação econômica que o Brasil está enfrentando, do crescimento demográfico e das condições sociais das famílias brasileiras.

As questões sobre a juventude vêm adquirindo um novo status no marco social. O mercado de trabalho tem sido alvo de muitas reflexões que se apresentam em torno de inúmeras análises que vão, desde os impactos de novas tecnologias ao seu retrocesso como critério de inclusão social e de poder político nas relações sociais.

Considera-se, também, que a taxa de desemprego tem crescido em consonância com a variável idade. O mercado tem preferido os jovens, devido aos menores encargos para contratação, bem como rescisão, isso contribui para o aumento de oportunidades nesse mercado, em detrimento dos mais velhos.

A justificativa pela escolha do tema da dissertação perpassa por apresentar as barreiras enfrentadas pelos alunos da Educação de Jovens e Adultos (EJA) em busca do primeiro emprego. Seu público constitui-se, majoritariamente, por indivíduos que tiveram passagens fracassadas pela escola, sendo excluídos do sistema regular. Nesse sentido, o grande desafio pedagógico, em termos de seriedade e criatividade que a Educação de Jovens e Adultos impõe e exige possibilitar a esse alunado. É uma educação que possa garantir seu espaço e sua inserção no mercado de trabalho, na participação ativa na política social do país, como sujeitos mais críticos e participativos.

As atuais mudanças demográficas, assim como o impacto das políticas de proteção social e as direcionadas para o trabalho, estão desempenhando importante papel sobre a maneira e as condições pelas quais os jovens brasileiros estão se introduzindo no mercado de trabalho nacional.

Os jovens e adultos que estão inseridos no mercado de trabalho, em muitos momentos se deparam com adversidades para poderem se manter no emprego, é neste momento que a qualificação se torna uma necessidade evidente.

Correia, Baltazar e Holanda (2019, s.p) revelam que: 
[...] a inserção do jovem no mercado de trabalho realiza-se de forma caracterizada, segundo a condição socioeconômica da sua família. Para as camadas com menor rendimento, o percentual de jovens que participam da População Economicamente Ativa (PEA), sejam eles ocupados e desempregados, é sempre inferior ao registrado para os jovens pertencentes às famílias com maior poder aquisitivo. Esta elevada proporção de inativos entre os jovens mais pobres está vinculada às crescentes dificuldades de entrada no mercado de trabalho, marcadas pelo crescimento do desemprego.

O problema da pesquisa foi pensar em: como se caracterizam as trajetórias percorridas por 30 estudantes da EJA para se inserir no mercado de trabalho cursando apenas o Ensino Médio?

O objetivo geral foi investigar as trajetórias percorridas pelos estudantes da EJA, na busca de inserção no mercado de trabalho. E os específicos foram:

a) Identificar os obstáculos e êxitos dos jovens e adultos para adentrar no mercado de trabalho por meio do questionário aplicado;

b) Analisar os dados coletados à luz da teoria que sustenta a investigação;

c) Elaborar um guia com orientações sobre a inserção no mercado de trabalho.

Com base no problema pesquisado, buscaram-se os referenciais que apoiaram as discussões e auxiliaram nas observações e nas falas dos jovens. Sendo assim, nos procedimentos metodológicos, definiram-se as técnicas e instrumentos para a execução da pesquisa. Realizou-se a transcrição de algumas entrevistas, na íntegra, e a análise dos dados em conformidade com os objetivos delimitados ao tema.

O trabalho encontra-se dividido em quatro capítulos. O primeiro é introdutório, onde foi descrita a relação desta pesquisadora com o objeto de pesquisa, destacando 0 interesse pelos alunos devido sua sintonia com a EJA, da qual é professora da 
disciplina de Sociologia. Ainda neste capítulo foi apresentado o problema de pesquisa, sua relevância, os objetivos que buscou alcançar e a fundamentação da justificativa.

O segundo capítulo traz um referencial teórico onde se abordam estudos sobre a Educação de Jovens e Adultos no Brasil e as mudanças nesta modalidade de ensino, tendo como referencial teórico diversos autores como Cunha (1999) que analisou a incapacidade do aluno analfabeto para a sociedade; Freire (2019) valorizou os saberes adquiridos e a importância do professor para os alunos da EJA; Raggi (2013) abordou os modelos educativos apropriados conforme a prática social da metodologia de projetos.

No capítulo três encontra-se retratada a metodologia (métodos e materiais) apresentando os procedimentos metodológicos adotados para a pesquisa, o local da pesquisa com um pequeno relato sobre a EEEFM Ana Lopes Balestreiro e o perfil dos sujeitos da pesquisa. No quarto capítulo, tem-se a descrição e análise dos dados descrevendo os resultados obtidos nas observações com o sujeito da pesquisa e as entrevistas realizadas, e o quinto capítulo apresenta o produto educacional seguido das considerações finais, com retomada dos objetivos e dos resultados obtidos, relacionando-os com a fundamentação teórica utilizada.

\section{HISTÓRICO DA EDUCAÇÃO DE JOVENS E ADULTOS (EJA) NO BRASIL}

Desde o Brasil Colônia que a Educação de Jovens e Adultos, no Brasil, vem se realizando, entretanto, as iniciativas governamentais no sentido de ofertar esta modalidade de ensino são recentes. Neste período, a referência à população adulta era somente de educação para a doutrinação religiosa, envolvendo um caráter muito mais religioso que educacional. No período do Brasil Império, algumas reformas educacionais começaram a acontecer e estas preconizavam a necessidade do ensino noturno para adultos analfabetos.

Em 1876, foi escrito pelo ministro José Bento da Cunha Figueiredo, um relatório que despontava a existência de 200 mil alunos que acompanhavam aulas noturnas. Por 
um período bem extenso, essas escolas eram a melhor opção para a educação de adultos que havia no país.

Segundo Cunha (1999, p. 25), o desenvolvimento industrial, no começo do século XX, desencadeou um processo lento, mas que foi aumentando para a valorização da educação de adultos, com indagações no que se aludia à educação. São elas: a importância do domínio da língua falada e escrita, buscando o domínio das técnicas de produção; a aquisição da leitura e da escrita, como instrumento da ascensão social; a alfabetização de adultos como uma forma de crescimento do país; a importância da alfabetização de adultos para o crescimento de votos.

A partir de 1940, iniciou-se uma pesquisa, sendo detectados altos índices de analfabetismo no país, o que fez com que o governo tomasse a decisão de criar um fundo destinado à alfabetização da população adulta. Com a criação da UNESCO[3] (Organização das Nações Unidas para a Educação, Ciência e Cultura) e, a partir dela, foi solicitado aos países integrantes, entre eles o Brasil, que se mobilizassem em função de educar os adultos analfabetos.

Com este fato, em 1947, o governo lançou a 1ํㅡ Campanha de Educação de Adultos, propondo: alfabetização dos adultos do país em três meses, oferecimento de um curso primário em duas etapas de sete meses, a capacitação profissional e o desenvolvimento comunitário. Nova discussão foi aberta sobre o analfabetismo e a educação de adultos no Brasil.

Nessa época, o analfabetismo era visto como causa (e não como efeito) da precariedade do desenvolvimento brasileiro. Além disso, "[...] o adulto analfabeto era identificado como elemento incapaz e marginal psicológica e socialmente, submetido à menoridade econômica, política e jurídica, não podendo, então, votar ou ser votado" (CUNHA, 1999, p. 25).

Essa primeira campanha foi lançada, de acordo com Soares (1996, p. 15), por dois motivos: inicialmente era o momento pós-guerra que estava presente no mundo, e que fez com que a ONU[4] escrevesse uma série de recomendações aos países, entre 
estas um olhar específico para a educação de adultos. O segundo motivo foi o final do Estado Novo, pois trazia um processo de redemocratização, que gerava a necessidade de ampliação do contingente de eleitores no país.

A partir da 1aㅡ Campanha, o SEA[5] (Serviço de Educação de Adultos) do MEC[6], criou e levou para discussões, aos SEAs estaduais, um conjunto de publicações sobre o tema. Nessas publicações havia várias concepções: o investimento na educação, como solução para problemas da sociedade; o alfabetizador, identificado como missionário; o analfabeto visto como causa da pobreza; o ensino de adultos como tarefa fácil; a não necessidade de formação específica; a não necessidade de remuneração, devido à valorização do "voluntariado" e a partir daí iniciou um processo de mobilização nacional no sentido de se discutir a educação de jovens e adultos no país.

Embora a Campanha não obtivesse sucesso, alcançou alguns resultados, no que se refere à visão preconceituosa. Esta se superou a partir das discussões que ocorreram sobre o processo de educação de adultos. Várias pesquisas aconteceram e algumas teorias da psicologia desmentiram a ideia de incapacidade de aprendizagem designada ao educando adulto.

O método de alfabetização adotado para a população adulta, nessa Campanha, recebeu muitas críticas, em relação à precária condição de funcionamento das aulas, a pouca frequência e baixo rendimento dos alunos; a má remuneração e ao despreparo dos professores; a falta de adequação do programa e do material didático à clientela e a superficialidade do aprendizado, pelo curto período designado para tal.

Dessa forma, a $1^{\text {a }}$ Campanha começou a fracassar, devido aos resultados insatisfatórios, porém, a delegação de Pernambuco ganhou destaque porque, além das críticas, foram apontando soluções; e quem fazia parte da delegação era Paulo Freire, que propunha uma maior comunicação entre o educador e o educando; e uma adequação do método às características das classes populares. 
Foi criada uma grande mobilização, por parte da sociedade civil, em torno das reformas de base, ao final da década de 50 e início da de 60, o que beneficiou a mudança das iniciativas públicas de educação de adultos. Uma visão diferente, sobre o problema do analfabetismo, foi surgindo, junto à consolidação de uma nova pedagogia de alfabetização de adultos, que tinha como principal referência Paulo Freire. Surgiu um novo paradigma pedagógico - um entendimento diferenciado da relação entre a problemática educacional e a problemática social.

"O analfabetismo, que antes era apontado como causa da pobreza e da marginalização, passou a ser, então, interpretado como efeito da pobreza gerada por uma estrutura social não igualitária" (SOARES, 1996, p. 15).

Nasceu a ideia de que o processo educativo deveria ser uma forma de modificar a estrutura social que produzia o analfabetismo, através da educação de base, partindo de um exame profundo da realidade em que os educandos estavam inseridos. As ideias de Freire de que a alfabetização é o domínio de técnicas para escrever e ler em termos conscientes e resulta numa postura atuante do homem sobre seu contexto, cresceram no país, o que rendeu a ele ser reconhecido nacionalmente por seu trabalho com a educação popular e, mais especificamente, com a educação de adultos.

A $1^{\text {a }}$ Campanha foi encerrada pelo Governo em 1963, que delegou a Paulo Freire a função de organizar e desenvolver um Programa Nacional de Alfabetização de Adultos. Porém, com o Golpe Militar em 1964, houve um rompimento desse trabalho, já que a conscientização, proposta por ele, passou a ser vista como ameaça à ordem instalada. Deu-se, a partir daí o exílio de Freire e o início da realização de programas de alfabetização de adultos assistencialistas e conservadores.

Em 1967, ainda nesse contexto, o Governo assumiu o controle da alfabetização de Adultos, com a criação do Movimento Brasileiro de Alfabetização (MOBRAL)[7], voltado para a população de 15 a 30 anos, cujo objetivo era a alfabetização funcional com aquisição de técnicas elementares de leitura, escrita e cálculo, esvaziando de 
todo sentido crítico e problematizador, proposto anteriormente por Freire, das orientações metodológicas e os materiais didáticos.

O crescimento do MOBRAL aconteceu na década de 70 , quando iniciou uma proposta de educação integrada, que tinha como objetivo a conclusão do antigo curso primário. Em contrapartida, alguns grupos que acreditavam na educação popular continuaram a alfabetização de adultos dentro da linha mais criativa. A Lei de Diretrizes e Bases da Educação, LDB 5692/71, implantou o Ensino Supletivo e, a ela, foi inserido um capítulo específico para a EJA. Esta lei limitou o dever do Estado à faixa etária dos 7 aos 14 anos, mas reconheceu a educação de adultos como um direito de cidadania, o que pode ser considerado um avanço para a área da EJA no país.

O MEC, em 1974, lançou uma proposta de implantação dos Centros de Estudos Supletivos (CES), que se articulavam entre o tempo, o custo e a efetividade. Entretanto, devido aos inúmeros acordos entre MEC e USAID[8], os cursos oferecidos tiveram uma enorme influência do tecnicismo, adotando-se os módulos instrucionais, o atendimento individualizado, a autoinstrução e a arguição em duas etapas - modular e semestral. Consequentemente, ocorreram a evasão, o individualismo, o pragmatismo e a certificação rápida e superficial.

Com a abertura política, nos anos 80 , as experiências que foram surgindo em relação a alfabetização, foram sendo desenvolvidas dentro de um formato mais crítico, e adquiriram formas, fazendo surgir os projetos de pós-alfabetização, que propunham um avanço na linguagem escrita e nas operações matemáticas básicas.

No lugar do MOBRAL, extinto em 1985, criou-se a Fundação EDUCAR, que desistiu de executar de forma direta os projetos, passando a dar apoio à parte financeira e, na técnica, com as iniciativas existentes. De acordo com Cunha (apud PORCARO, 2019, s.p), "[...] a década de 80 foi marcada pela difusão das pesquisas sobre língua escrita com reflexos positivos na alfabetização de adultos". Com a Constituição, promulgada em 1988, o Estado teve a ampliação de seu dever para com a EJA e, com isso, garantiu o ensino fundamental, tornando-o obrigatório e gratuito para todos. 
O desafio da Educação de Jovens e Adultos, nos anos 90, passou a ser a criação de uma política e de metodologias criativas, com o Ensino Fundamental de qualidade e universalizado. Essa modalidade de ensino teve seu reconhecimento internacional e fortaleceu a cidadania e a formação cultural da população, por causa das conferências estabelecidas pela UNESCO, criada pela ONU a qual foi responsabilizada por incentivar a educação nos países em desenvolvimento. Organizaram os Fóruns Estaduais da EJA, que crescem em todos os estados brasileiros, com exceção de Roraima.

O artigo $3^{\circ}$ da LDBEN 9.394/96 (BRASIL, 2004) trouxe um estímulo para a criação de propostas alternativas na área de EJA:

Art. $3^{\circ} \mathrm{O}$ ensino será ministrado com base nos seguintes princípios:

I - Igualdade de condições para o acesso e permanência na escola;

II - Liberdade de aprender, ensinar, pesquisar e divulgar a cultura, o pensamento, a arte e o saber;

III - pluralismo de ideias e de concepções pedagógicas;

IV - Respeito à liberdade e apreço à tolerância;

V - Coexistência de instituições públicas e privadas de ensino;

VI - Gratuidade do ensino público em estabelecimentos oficiais;

VII - Valorização do profissional da educação escolar;

VIII - Gestão democrática do ensino público, na forma desta Lei e da legislação dos sistemas de ensino;

IX - Garantia de padrão de qualidade;

X - Valorização da experiência extraescolar; 
XI - Vinculação entre a educação escolar, o trabalho e as práticas sociais.

Apesar da Lei ter dedicado apenas uma sessão com dois artigos à EJA $\left(2^{\circ}, 3^{\circ} \mathrm{e}\right.$ $4^{\circ}$ ), referem-se a ela sob o prisma do Ensino Fundamental, o que se considera um ganho para a área. Além disso, ao determinar a identificação daqueles que não tiveram acesso ao Ensino Fundamental, abriu uma brecha para a intervenção e criou possibilidades de confronto entre o universo da demanda e o volume e qualidade da oferta, o que pode gerar um maior compromisso do setor público com a EJA.

$\mathrm{Na}$ década de 90 , os municípios passaram a ter responsabilidade com a EJA, pois o governo se desobrigou de articular a política nacional. Inúmeras iniciativas vão emergindo, ocorrendo parcerias entre municípios, ONG's e Universidades, fazendo surgir os fóruns de EJA, como espaços de encontros e ações em parceria entre os diversos segmentos envolvidos nesta modalidade, com 0 poder público (administrações públicas municipais, estaduais e federal), com as universidades, sistemas, ONG's, movimentos sociais, sindicatos, grupos populares, educadores e educandos.

O objetivo deste Fórum foi, entre tantos, fazer a troca de experiências e o diálogo entre as instituições. Os fóruns articulam instituições, socializam iniciativas e intervêm na elaboração de políticas e ações da área de EJA. Estes ocorrem num movimento nacional, com o objetivo de interlocução com organismos governamentais para intervir na elaboração de políticas públicas. Eles acontecem de diversas formas, porém, o Rio de Janeiro é o primeiro estado a criar um Fórum Estadual de EJA.

Em 2001 organizou, em Brasília, uma reunião para compreender os desafios dos fóruns sobre a EJA, concluindo-se que têm o objetivo de socializar informações e trocar experiências, sendo um espaço de pluralidade. Eles surgem como uma estratégia de mobilização das instituições do país que estão diretamente envolvidas com a EJA, pois o MEC se ausenta da qualidade de articulador de uma política nacional para essa modalidade de ensino. 
A partir de 1997, com o surgimento dos fóruns, a história da EJA passa a ter um Boletim da Ação Educativa, onde tudo é registrado e socializa uma agenda desses momentos e os relatórios dos ENEJAs[9]. De 1999 a 2000, então, os fóruns passam a ser uma presença constante nas audiências do Conselho Nacional de Educação para discutir as diretrizes curriculares para a EJA.

\subsection{A EDUCAÇÃO DE JOVENS E ADULTOS APÓS A NOVA LDBEN}

As escolas públicas do Brasil iniciam, a partir de 1996, um complexo processo de transição. Foi extinto o ensino supletivo e se implantou a Modalidade EJA no Ensino Fundamental e Médio, buscando a emancipação do educando através de um permanente processo de ensino aprendizagem. Não obstante, a realização da $5^{\mathrm{a}}$ Conferência Internacional sobre Educação de Jovens e Adultos (CONFINTEA)[10] realizada em julho de 1997, na Alemanha, lançou, em seus documentos, uma série de orientações a serem seguidas pelos sistemas educacionais que implementaram essa nova modalidade de ensino.

As intensas transformações socioeconômicas e culturais das últimas décadas motivaram a produção dessas recomendações com vistas ao desenvolvimento de estratégias educacionais para a produção de conhecimento e aprendizagem permanentes e ao longo da vida.

De acordo com os documentos elaborados pela CONFINTEA, os cursos de EJA são preparados para a alfabetização do cidadão e sua transição pela sociedade, revelando um sujeito crítico e participativo na esfera social; a preparação permanente dos educadores visando qualificar as suas ações pedagógicas; a aprendizagem de competências e habilidades que possam dar aos jovens e adultos, amparo para lidar com as tecnologias e, desta forma, conseguir acompanhar as frequentes transformações globais e os impactos, por ela, causados.

O documento revela a construção de propostas educacionais que favoreçam o desenvolvimento de valores solidários, de justiça e tolerância, mediante o uso da autonomia e do senso crítico do jovem e adulto inserido na sociedade. Outros valores 
como, o respeito aos saberes ditos não formais, produzidos pelos jovens e adultos ao longo da vida e, a elaboração e implementação de um currículo diversificado e flexível, de acordo com a realidade sociocultural do educando, serão analisados mais adiante.

A criação de documentos internacionais sobre a EJA forçou o Brasil a fazer compromissos para que o público jovem e adulto fosse bem atendido, sobretudo se analisadas as taxas de analfabetismo do país, consideradas altas em comparação com outras nações. Nesse sentido, a nova Lei de Diretrizes e Bases da Educação Nacional, aprovada em 1996, instituiu a obrigatoriedade da oferta de EJA para aqueles que não tiveram acesso ou não deram continuidade aos estudos na idade regular.

A LDB determina a obrigatoriedade da oferta de educação gratuita por todos os sistemas públicos de ensino. A legislação cria diferentes mecanismos em níveis federal e estadual, como Pareceres e Resoluções, a fim de legalizar cada vez mais as estruturas balizadoras da Educação de Jovens e Adultos. A Resolução CNE/CEB no 1 , de 5 de julho de 2000, que estabelece as Diretrizes Curriculares Nacionais para a Educação e Jovens e Adultos e o Parecer 11/2000 do Conselho Nacional de Educação, que faz referência às Diretrizes Curriculares Nacionais para a Educação de Jovens e Adultos são fundamentais para compreender como está organizada a Modalidade EJA no sistema de ensino brasileiro.

De acordo com a Lei no 9.394/96 (BRASIL, 1996), "[...]educação de jovens e adultos será destinada àqueles que não tiveram acesso, ou continuidade de estudos no Ensino Fundamental e Médio na idade própria". Esta mesma lei estabelece que:

[...] os sistemas de ensino assegurarão gratuitamente aos jovens e adultos que não puderam efetuar os estudos na idade regular, oportunidades educacionais apropriadas, consideradas as características do alunado, seus interesses, e condições de vida e de trabalho mediante cursos e exames (BRASIL, LDBEN, 1996). 
Percebe-se, então, que há uma vontade política de favorecer a cada dia a permanência do aluno na escola, proporcionando meios de concluir seus estudos em pouco tempo.

Freire (2019, p. 49) relatou que "[...] não há saber mais ou menos; há saberes diferentes", mostrando que o saber popular é de grande importância para o professor, que ministra suas aulas na EJA.

Ensinar a jovens e adultos exige uma relação professor-aluno de conscientização, de mediação e de incentivo, pois tudo que o docente faz em sala de aula torna-se de grande influência na apropriação dos conceitos, pois a maioria desses alunos vem de um dia cansativo de trabalho e muitos anos sem frequentar a escola.

\subsubsection{APRENDIZAGEM DE JOVENS E ADULTOS DA EJA}

Os alunos jovens e adultos da EJA são pessoas, em sua maioria, que retornam aos estudos, após um tempo afastadas da escola. São personagens principais das histórias reais e ricos em experiências vividas e com valores e crenças constituídos, cuja visão de mundo é favorecida por suas raízes culturais e por vivência social, familiar e profissional. Uma noção de mundo mais relacionada ao ver, do que fazer.

Aberto às aprendizagens, eles vêm para a sala de aula com um olhar que é, por um lado, um olhar receptivo, sensível, e, por outro, é um olhar ativo: curioso, explorador, investigador, interrogativo. Vêm com inúmeros conhecimentos adquiridos ao longo de sua história de visa. Esses conhecimentos de vida são o saber sensível e o saber cotidiano (BRASIL, 2006, p. 5).

O saber sensível está relacionado ao saber do corpo, originado na primeira relação com o mundo e firmado na percepção do outro e de tudo que o cerca. Um saber que antecede a reflexão. Este saber é firmado pelos cinco sentidos e que todos podem ter, mas é pouco valorizado. Esse tipo de saber não é considerado por grande parte 
da classe doente, portanto, não é estimulado nos espaços escolares, pois muitos professores atribuem sua exploração apenas às aulas de artes.

$\mathrm{Na}$ prática docente cotidiana, observou-se que esses alunos jovens e adultos, adquirem o saber sensível na experiência de vida, são plenos deste saber. Quase a maioria deles é receptiva às situações de aprendizagem, demonstrando encantamento e prazer mediante os procedimentos, os novos saberes e as vivências proporcionadas pela escola. Esses sentimentos precisam ser cultivados, pois são a porta de entrada para o exercício do raciocínio lógico, a reflexão, a análise, a abstração e com eles a construção um novo saber - o conhecimento científico.

O saber cotidiano se configura como o que reflete a vida, por ser da vivência de cada um e formado fora da escola. Esse saber possui uma concretude, proveniente da produção de soluções que surgiram com os seres humanos para os mais variados desafios que vivenciam. São caracterizados como um saber aprendido e consolidado em hábitos e modos de pensar no dia a dia. É o saber das ruas, o "senso comum", que é diferente do conhecimento formal elaborado com e na escola. É um saber pouco valorizado no mundo letrado escolar e pelo próprio aluno.

É o saber científico que leva o jovem à busca pela escola. Ele não decide de forma simples. É embalado pela família, sofre pressões dos patrões, está sujeito às precárias condições de acesso e as distâncias entre a casa e a escola podem se construir em obstáculos; muitas vezes são escassas as possibilidades de custear os estudos e, na maioria das vezes, sua trajetória para conquistar um espaço na escola se transforma em um processo de idas e vindas, de ingressos e desistências, de fracassos e derrotas.

A escola que eles possuem, em seu imaginário, é aquela que muitos já frequentaram outrora ou aquela que acompanham seus filhos, e nem sempre é a que se deparam nos primeiros dias. Eles esperam encontrar uma escola tradicional, com aulas expositivas, com conteúdos espalhados na lousa para serem copiados, sendo o professor o detentor do saber e aquele que irá transmitir todos os conteúdos e eles 
serão recebidos, passivamente, pelo aluno. No entanto, esse modelo pedagógico já não atende mais aos interesses e nem os prepara para o mundo do trabalho.

A formação dos jovens e adultos requer modelos educativos apropriados, que os coloquem em contato com a prática social concreta. Nesse sentido, Raggi (2019, p. 96), constatou, em sua tese de doutoramento, que a metodologia de projetos é uma estratégia de aprendizagem baseada em projetos educativos, que promove a articulação entre diversas áreas do saber, contextualiza o ensino e parte da realidade dos alunos. Essa perspectiva pedagógica compreende:

[...] um conjunto de técnicas e processos pedagógicos usados para integrar as diversas áreas do saber e construir conhecimentos centrados em problemas reais, na busca de solução para os mesmos, por meio de pesquisas científicas e da obtenção de um produto concreto (RAGGI, 2013, p. 96).

Os estudantes, ao se encontrarem diante de uma sala de aula, onde são convidados a pensar juntos, a expor suas experiências e opiniões em grupo, a tentar encontrar soluções para seus receios, realizar diferentes exercícios daqueles mais convencionais, ler textos literários; aprender com a música, entender a matemática utilizando jogos e cálculos diversos, construir projetos, se assustam, rejeitam e pensam que este não é o caminho certo para aprender.

A metodologia de projetos é uma estratégia de aprendizagem baseada em projetos educativos. De acordo com Raggi (2013, p. 96),

Metodologia de Projetos é um conjunto de técnicas e processos pedagógicos usados para integrar as diversas áreas do saber e construir conhecimentos centrados em problemas reais, na busca de solução para os mesmos, por meio de pesquisas científicas e da obtenção de um produto concreto.

Ainda nas colocações de Raggi (2013, p. 98), 
[...] o trabalho com projetos permite o estabelecimento de um vínculo entre os conteúdos e os problemas reais e certamente, é uma possibilidade de alunos e professores, participarem e transformarem em aprendizagem as experiências sociais como revelaram Hernández e Ventura (1998, p.10). Se o adulto aprende melhor quando percebe significado na informação ou conteúdo que a ele se apresenta, quando interage com sua cultura, com sua história, assumindo compromissos com sua aprendizagem e com a comunidade, a realização dos projetos sinaliza um caminho interessante de desenvolvimento da aprendizagem para a EJA.

É importante que a escola invista no acolhimento desses alunos, que devem ser receptivos à aprendizagem, que sejam curiosos e desejosos de aprender, pois grande parte desses, que buscam a escola, esperam dela um espaço que atenda às suas necessidades como pessoas e não apenas como alunos, que apesar da maturidade, passaram boa parte de seu percurso escolar tendo que trabalhar para manter o sustento da casa, ou por uma série de reprovações e, por este motivo, estão defasados em conhecimentos básicos e com baixa estima, devido à idade.

Para Freire (2011, p. 30), "[...], ensinar exige respeito aos saberes dos educandos", desmistificando o que eles pensam: que nada sabem e que nada irão aprender. $O$ principal desafio consiste em fazer uma escola na qual professores e alunos se veem como sujeitos com a missão de construir conhecimentos, que sejam amparados na perspectiva daqueles que aprendem. Os jovens e adultos procuram, na escola, muito mais que conteúdos prontos a serem reproduzidos. Eles querem se sentir sujeitos ativos, participativos e aptos para a aquisição de conhecimentos culturais, sociais e econômicos.

Os jovens e adultos que integram as salas de aula da EJA possuem uma diversidade de origens. Deparam-se com pessoas que migraram de suas cidades de origem em busca de condições de vida melhores, de trabalho, moradia, estudos e de novas oportunidades. O movimento migratório é declarado, nas salas, por meio dos traços físicos, modos de falar, agir e reagir, formas de lazer, preferências culinárias, musicais, 
etc.; uma diversidade de cultura. Em certas regiões, é comum encontrarmos alunos e alunas que saíram do campo, de um espaço rural para a cidade, a fim de dar continuidade nos estudos ou para obter um trabalho fixo.

Em 1960, Freire reconheceu o analfabetismo como uma questão não só pedagógica, mas também social e política. "[...] Educar a favor dos pobres é educar para a transformação da sociedade geradora da pobreza" (FREIRE apud BRASIL, 2006, p. 16). Outro fator que chama a atenção para esses alunos é a autoestima. A maioria é baixa e reforçada pelas situações de fracasso escolar.

Após análise das definições de autoestima, chegou-se à conclusão de que o professor, como formador de opinião, exerce influência na motivação do educando, percebendo que, como profissionais, são capazes e competentes para incentivá-lo de forma positiva.

Sua eventual passagem pela escola pode ter sido marcada pela exclusão e/ou pelo fracasso escolar. Seu desempenho pedagógico anterior foi comprometido, e sua volta à sala de aula pode revelar uma autoimagem fragilizada, que expressa sentimento de insegurança e de desvalorização pessoal frente aos novos desafios que se impõem.

Esse fracasso escolar é hoje um objeto de estudo nas áreas da Educação e da Psicologia. Suas causas apontam para uma diversidade e complexidade de fatores, ligados ao psiquismo do aluno: forma como ele interage com o ambiente escolar, modo como estabelece relações com o saber e com o aprender, seu relacionamento com os professores e com os colegas, suas relações familiares, os vínculos que constrói com o conhecimento, etc.; á estrutura da escola: as características, o modelo pedagógico adotado, o perfil dos professores. etc.; a uma dimensão social ampla: políticas públicas de educação e a secular desigualdade econômica e social da sociedade brasileira (BRASIL, 2006, p. 16).

O fracasso escolar tece uma teia, onde o aluno se enreda e custa se desvencilhar. A teia se torna tão emaranhada que não oferece saída, causando o desfecho comum, o 
abandono da escola. A pesquisa de Marcelo Neri (2009, p. 5), no ano de 2009, revelou, em percentuais, os fatores que causam o abandono escolar: 10,9\% possuem dificuldades de acesso à escola; $27,1 \%$ têm necessidade de trabalho e gerar rendas; $40,3 \%$ têm falta intrínseca de interesse e $21,7 \%$ possuem outros motivos para não frequentar a escola. Sabe-se que o cansaço diário dos diferentes tipos de trabalho faz com que este indivíduo não deseje mais estudar. Os interesses perpassam por manter a comida na mesa, se vestir e sustentar a família.

O cansaço da vida laboral e as dificuldades para a sobrevivência contribuem para o cansaço mental fazendo com que muitos desistam.

Patto (2015, p. 59) relata que:

A reprovação e a evasão escolar são: um fracasso produzido no dia-adia da vida na escola e na produção deste fracasso está envolvido aspectos estruturais e funcionais do sistema educacional, concepções de ensino e de trabalho e preconceitos e estereótipos sobre a sua clientela mais pobre.

São preconceitos que não se apresentam apenas pelos educadores, eles estão disseminados há décadas na literatura educacional enquanto discurso ideológico. É muito comum presenciarmos em sala de aula ideias preconcebidas sobre o aluno que apresenta dificuldades em sua aprendizagem, que é qualificado de forma pejorativa pelos professores, pais e colegas como "burro", "preguiçoso", "deficiente", "lento" etc. As palavras ferem a autoestima imprimindo umas cicatrizes profundas, que causam um efeito devastador no sujeito.

É notório que o sucesso eleva a autoestima, enquanto o fracasso causa grandes estragos na relação consigo mesmo, ferindo a autoimagem do aluno jovem e adulto. Estas marcas são evidentes na sala da EJA. Por um lado, atitudes de irreverência e transgressão, por outro, atitudes de extrema timidez e retração. Observa-se, no cotidiano, que são alunos que demonstram vergonha de perguntar ou responder, nervosismo em situações de avaliação, ou são muito indisciplinados e agitados. 
Muitos têm dificuldades de olhar nos olhos do professor, por se sentirem envergonhados.

A autonomia, a dignidade e a identidade do educando têm de ser respeitada para evitar que o ensino se torne "inautêntico, palavreado vazio e inoperante" (FREIRE, 2002, p. 69). isto só é possível quando se leva em consideração os conhecimentos adquiridos pelas experiências das crianças e adultos antes de chegarem à escola.

O professor deve pensar que, por meio da educação, também se fazem transformações sociais, mas deve ter a consciência da sua indevida utilização como meio de reprodução de ideologias dominantes. O bom professor, para Freire (2011, p. 162), "[...] não deve ser completamente apolítico, por expor suas opiniões e ensinando vários conceitos baseados em sua visão de mundo, porém pode demonstrar que é possível mudar, reforçando a importância da sua tarefa político-pedagógica".

Além dessa importante tarefa, a afetividade não deve assustar o docente, que muitas vezes tem medo de expressá-la. Deve-se ter afetividade, sem deixar o respeito e a autoridade de lado.

O papel do professor é fundamental para evitar essas situações e mais um fracasso escolar. O docente deve valorizar os saberes que os alunos trazem para a sala de aula, reconhecendo que existe uma sabedoria no sujeito que vem da sua experiência de vida, de seu conhecimento cultural, de suas habilidades profissionais, contribui para que ele resgate uma autoimagem positiva, e amplia sua autoestima fortalecendo sua autoconfiança. Acolher e valorizar o aluno possibilita a abertura de um canal de aprendizagem com maiores garantias de êxito.

Além dos problemas da autoestima, os alunos da EJA, em sua maioria, são trabalhadores e, muitas vezes, começaram a trabalhar cedo, e já eram responsáveis pelo cuidado com a casa, com os irmãos mais novos, porque os pais saíam para laborar e Ihes davam a responsabilidade da casa. Outras vezes, os filhos os acompanhavam, ajudando-os em pequenas tarefas. 
Nas regiões rurais, esses alunos começam a participar do trabalho ainda crianças, quando vão para as plantações, cuidam da terra ou da criação de animais; auxiliam nos serviços caseiros. Nessas regiões, os horários, os períodos da colheita, de chuva e de seca marcam a vida cotidiana das pessoas.

Boa parte dos alunos da EJA são sujeitos que trabalham e, após um dia de labuta, chegam à escola e, nas salas, apresentam um número grande de sujeitos desempregados e de trabalhadores que exercem funções em serviços temporários e informais. Entretanto, é preciso lembrar que as funções exercidas pelos alunos não passam, nem de longe, pelo trabalho como atividade fundamental pela qual o ser humano se humaniza e aperfeiçoa. A juventude, hoje, está mais crítica e consciente da sua importância e busca construir seus conhecimentos, preparando-se para 0 mercado de trabalho.

\subsection{A JUVENTUDE ATUAL}

Com a globalização, jovens e adultos se veem obrigados a ter contatos tecnológicos e, para isto, é necessário que possuam conhecimentos. A Organização das Nações Unidas (ONU) define jovem ou juventude como sendo a pessoa entre 15 e 24 anos, período esse em que alcança a maturação biológica, psicológica e social o que the permitirá uma completa condição de participar das relações sociais do mundo adulto. Sendo "[...] um exercício complexo, pois corresponde a construções sociais nem sempre presentes nas sociedades nem manifestadas da mesma forma ao longo da história de uma dada sociedade" (BRASIL, 2019, s.p).

Considera-se que ao se pensar em juventude, intenciona-se designar uma fase da passagem da vida humana em que os adultos não têm mais cuidado com este membro da comunidade para que possa passar da condição de dependente para uma referida independência, colaborando com a sustentação da vida coletiva.

Para a definição de juventude, é importante compreender as contradições presentes nesse segmento da população, devido suas especificidades e desigualdades que são produzidas por razões históricas, sociais e culturais, em vez de uma juventude 
homogênea, conforme sua faixa etária. A juventude precisa ser pensada em suas diferentes condições produzidas pelos meios sociais em que convivem.

De acordo com Novaes (2019, p. 5), na Política Nacional de Juventude,

A juventude é uma condição social, parametrizada por uma faixa etária, que no Brasil congrega cidadãos e cidadãs com idade compreendida entre os 15 e os 29 anos. [...] Em termos políticos e sociais, os jovens são sujeito de direitos coletivos. Sua autonomia deve ser respeitada, suas identidades, formas de agir, viver e se expressar valorizadas.

A Política Nacional de Juventude (PNJ)[11], no Brasil, divide a faixa etária dos 15 aos 29 anos em 3 grupos: 15 aos 17 anos são jovens-adolescentes; 18 a 24 anos são jovens-jovens e dos 25 aos 29 anos são jovens-adultos. Sendo que o primeiro grupo está incluído na política da criança e do adolescente.

A presença de jovens e adultos no mercado de trabalho é assinalada pela desigualdade. É notório, que a inserção das jovens no mercado de trabalho é bem superior em todas as regiões analisadas e conserva a similaridade com a taxa de participação dos homens jovens, o que favorece as alterações de comportamento das novas gerações a caminho de uma maior igualdade nas relações de gênero. Fato que se realiza conforme a condição socioeconômica das famílias. Para as pessoas com menor rendimento, o percentual de jovens e adultos ocupados ou desempregados, é sempre inferior ao registrado para os que pertencem às famílias com maior poder aquisitivo. Este aumento de inativos, entre os jovens mais pobres, está referenciando às crescentes dificuldades de entrada no mercado de trabalho, marcado pelo crescimento do desemprego.

O jovem brasileiro está alcançando um status político e social cada vez mais notável, ainda que vivendo em processo de consolidação. O que marca esse processo é a não acomodação da juventude em ser somente um objeto das ações sociais e das políticas públicas. Na linha histórica da juventude, têm-se características que revelam cada época vivida por esta fase da vida, segundo Dick (2016, p. 237): 
Quadro 1 - Principais características dos jovens e sua representação nas décadas

ANOS 40 Jovens marcados pelas experiências chocantes vividas durante a Segunda Guerra Mundial e com as bombas atômicas no Japão.

ANOS 50 "Anos Dourados" - jovens mais autônomos.

ANOS 60 Década onde o tema JUVENTUDE foi mais explorado, expansão do Movimento hippie como uma ameaça à ordem social. I

ANOS 70 "Anos de ressaca" - juventude insatisfeita, buscando mudanças para sair de uma sociedade estagnada, apática e viciada.

ANOS 80 Defesa do protagonismo juvenil através da "Pastoral Juvenil" e redução dos avanços da liberdade sexual através da difusão da AIDS; jovens sem ideologia, individualistas, consumistas e conservadores.

ANOS 90 Transição de uma geração que valorizava a organização, a articulação, a lógica e o raciocínio, para uma geração que valoriza o corpo, o prazer, o fragmentado e o individual. Surge a "geração zapping" (em constante mudança).

ANOS A geração $Y$, costuma ser conhecida como geração Internet, se 2000 constituindo por indivíduos que nasceram entre os anos de 1980 a 2000. São conectados, devido terem sido criados na era da informação e dos avanços tecnológicos.

Anos Os jovens da geração $Z$ antecipam e simplificam muita coisa - pontos 2010 extremamente positivos no mundo corporativo. São profissionais com uma compreensão tecnológica apurada, abertos a novas tecnologias e com raciocínio rápido. Essas características acabam gerando certa impaciência, e a rotina frequente atrelada a processos burocráticos pode ser desanimadora para esses jovens.

Anos São jovens chamados de Millennials por terem sido incentivados desde 2020 infância a acreditar que merecem estar à frente das coisas. São assertivos, desejam feedbacks regulares e gostam de receber elogios e críticas.

Fonte: Dick, 2016, p. 237 
Diante do quadro apresentado, considera-se a juventude como resultante de uma vivência em certo período histórico e social, trazendo informações da cultura onde ela é constituída e o tempo pelo qual ela é arquitetada. Inseridos nos conceitos hegemônicos da sociedade contemporânea, os jovens se apresentam assustados e inseguros e drasticamente imediatistas. "A imagem do jovem que se cristalizou na sociedade atual traz uma forte característica de metamorfose, de aglutinação, de inconstância, de incerteza e de desvinculação, enquanto representação de uma categoria fragilizada e vulnerável" (GUIMARÃES; GRINSPUN, 2019, p. 8). Em compensação, os jovens representam, também, uma categoria que tem consciência e aceita desafios ao se propor em buscar novos valores sociais, morais e afetivos, que possam reestruturar sua identidade. Hall $(2014$, p. 13) destaca que a identidade vai se formando por meio de um processo histórico, e não biológico, e que "[...] o sujeito assume identidades diferentes, em diferentes momentos, identidades que não são unificadas ao redor de um "eu" coerente".

\subsection{OS (DES) CAMINHOS DO PRIMEIRO EMPREGO}

Analisando o processo de inserção do jovem e do adulto no mercado de trabalho brasileiro pensa-se que não pode ser dissociado das características concentradoras e excludentes do desenvolvimento socioeconômico brasileiro, responsável pela construção de uma das nações com os mais elevados índices de desigualdade econômica, regional e entre diversos segmentos da sociedade.

A pesquisadora Sonia Rocha (2019, s.p) relatou que:

[...] para os jovens, ter alguma experiência de trabalho é mais importante que a escolaridade, Há evidências empíricas que, para os indivíduos de 15 a 24 anos, o mercado de trabalho valoriza mais a experiência que a escolaridade e um ano a mais de experiência aumenta em $20 \%$ a probabilidade do jovem estar ocupado, enquanto um ano a mais de escolaridade aumenta essa probabilidade em apenas $1 \%$. 
É bem possível que haja o crescimento da escolaridade, porém a postergação de entrada no mercado de trabalho, tenha significado no futuro, elevando as taxas de desemprego para a faixa etária com mais de 25 anos, significando que uma parcela dos não jovens terá mais dificuldades de inserção, relacionada à falta de experiência.

O gráfico abaixo apresenta o percentual de desempregados por gênero, idade e escolaridade, revelando que quem mais sofre com o desemprego são as mulheres, os indivíduos com mais de 40 anos e aqueles que possuem o Ensino Médio incompleto.

Gráfico 1 - Desempregados que buscam emprego há 2 anos, ou mais, em 2019, por gênero, idade e escolaridade (Em \%)

\section{Desempregados}

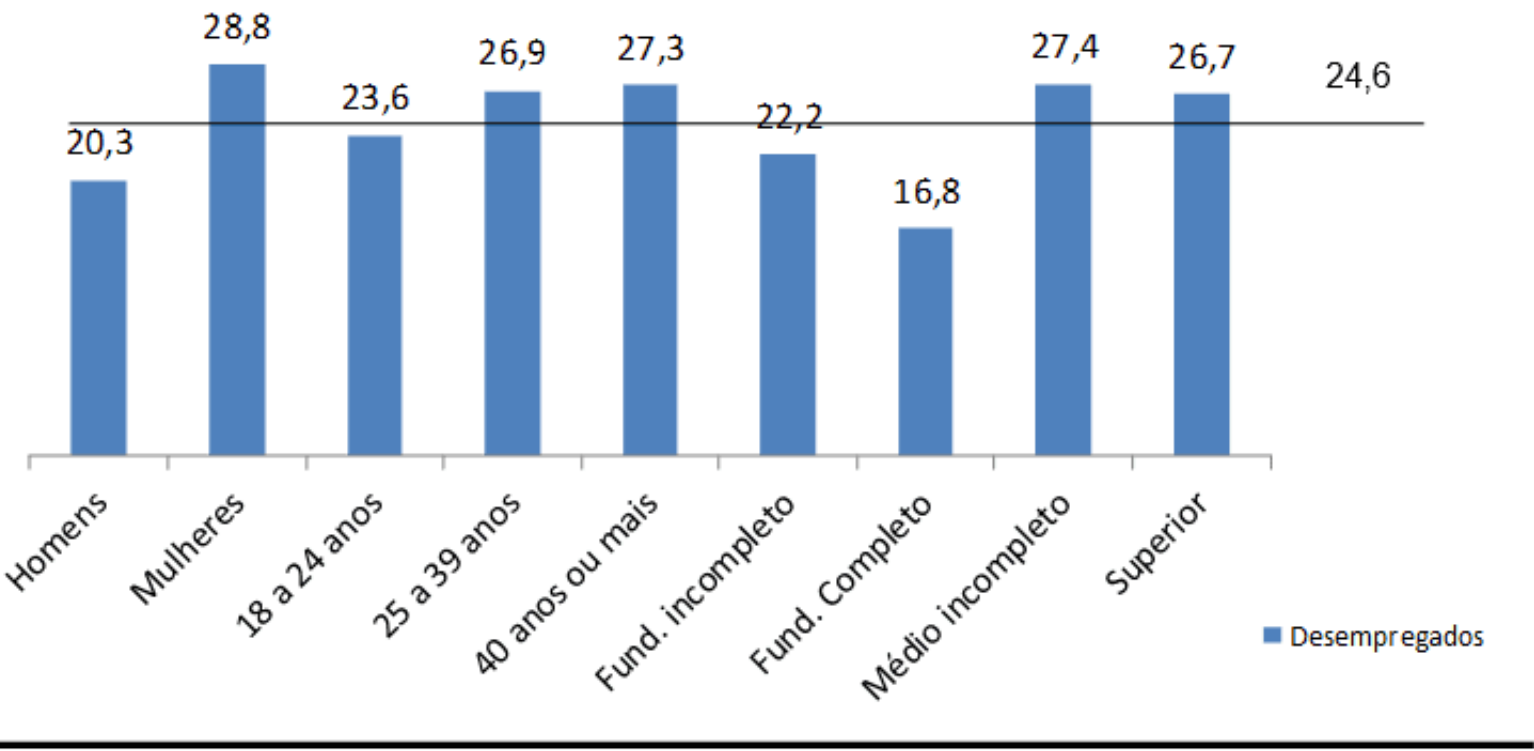

Fonte: LAMEIRAS, 2019, p. 4

O gráfico 1 revela a parcela de desempregados, por dois anos, para um número variado; grupos que foram definidos pelas características individuais. De acordo com Lameiras et. al. (2019, p. 4), 
Essa parcela é maior que a média nacional (representada pela barra horizontal) para mulheres, para adultos com mais de 40 anos de idade, e para indivíduos com nível educacional igual ou superior ao ensino médio completo. Entre esses grupos, chama atenção a parcela de 28,8\% de mulheres desempregadas que estão nessa condição há pelo menos dois anos, vis-à-vis uma porcentagem análoga de 20,3\% para os homens. Além da caracterização estática, é importante ter uma noção de como cresceu, nos grupos, a parcela de desempregados nessa condição há pelo menos dois anos. $\mathrm{O}$ crescimento dessa parcela no Brasil foi de $42,4 \%$ entre os primeiros trimestres de 2015 e 2019. O gráfico neste box revela que essa taxa de crescimento foi superada em larga escala pela registrada entre os homens $(79,3 \%)$, e a registrada entre os jovens $(56,6 \%)$.

No segundo semestre do ano de 2018, segundo pesquisa realizada pelo IBGE (LAMEIRAS, 2019, p. 2), a taxa de desemprego entre os trabalhadores na faixa etária entre 18 e 24 anos foi o dobro da taxa da população geral. Esta última ficou em 12,4\% no segundo trimestre; entre os jovens, esse percentual passou para $26,6 \%$. A taxa revela ser maior o desemprego entre os jovens, devido às barreiras impostas pela falta de escolaridade e a falta de experiência profissional, o que leva as empresas a buscar quem já tem experiência devido ao alto custo para capacitação desses indivíduos.

Lameiras et. al.(2019, p. 3) declara que:

[...] os micro dados da Pesquisa Nacional por Amostra de Domicílios (PNAD) Contínua, mostra que, no primeiro trimestre de 2019, a proporção de desempregados há mais de dois anos era maior entre as mulheres (28,8\%), entre os adultos com mais de 40 anos $(27,3 \%)$ e entre os trabalhadores com ensino médio completo $(27,4 \%)$. No caso dos trabalhadores mais jovens, esse resultado acaba por corroborar um cenário de emprego ainda mais adverso, que combina desemprego 
elevado (27,3\%), baixo crescimento da ocupação $(0,4 \%)$ e queda de rendimentos $(0,8 \%)$.

A situação dos jovens e adultos, que estão à margem de risco do desemprego, inspira atenção, dadas as evidências disponíveis na literatura sobre o prejuízo que uma passagem pelo desemprego, no início da carreira profissional, traz para sua trajetória, mesmo a médio e longo prazo. O grau de escolaridade revela que os trabalhadores com instrução mais baixa apresentam perdas significativas de desemprego, ao longo do primeiro trimestre de 2019. Os trabalhadores com Ensino Fundamental incompleto ou completo, recuo que se deu pelo fato da retratação da força de trabalho (LAMEIRAS, 2019, p. 5).

Apesar da maior taxa de desemprego ser a dos trabalhadores com Ensino Médio incompleto, os micro dados de transição revela que a crise no mercado de trabalho, independente da escolaridade, gerou uma queda no percentual de desempregados que ocuparam as vagas dos que foram demitidos. Em contrapartida, do mesmo modo que os trabalhadores com Ensino Médio incompleto conseguem obter uma chance no mercado de trabalho, eles têm a maior probabilidade de serem dispensados pelo baixo nível de escolaridade ou pela ausência de qualificação profissional (LAMEIRAS, 2019, p. 5).

Em busca de trazer respostas ao problema desta pesquisa, verifica-se, nos estudos levantados, o que se constata na prática social concreta: as trajetórias percorridas pelos jovens da EJA, para encontrar uma vaga de trabalho com apenas o Ensino Médio tem sido de grande dificuldade. Conforme a fala de Limeira, no parágrafo acima, a ausência de qualificação profissional, ou a baixa escolaridade, é, de fato, preponderante para essa classe de trabalhadores, que tenta se colocar diariamente no mercado de trabalho. 


\section{METODOLOGIA}

Este capítulo apresenta os procedimentos metodológicos adotados para a elaboração da presente pesquisa, levando em consideração o contexto, o tipo de pesquisa, os procedimentos, os instrumentos e a análise dos dados coletados.

\subsection{PROCEDIMENTOS METODOLÓGICOS}

Os procedimentos metodológicos exigiram o contato próximo com os sujeitos, no contexto em que o fenômeno acontece. Também foi reconhecida a relatividade da análise dos fatos para comprovação do estudo apresentado.

O estudo de caso, como pesquisa descritiva, está embasado em Yin (2001, p. 33) que relata a sua importância, explicando que, este, procura esclarecer sobre uma ou um conjunto de decisões, debatendo as razões que levaram as tomadas de decisões, como estas foram implantadas e quais resultados foram alcançados.

Levou-se em consideração o envolvimento direto da pesquisadora com a pesquisa, visto que foi realizada no ambiente profissional (sala de aula), e o desejo de colaborar com o crescimento dos alunos da Educação de Jovens e Adultos, motivando-os a buscar, a cada dia mais seu aprimoramento intelectual e profissional, para que, no futuro, possam ter qualificação de forma que possam alcançar vagas no mercado de trabalho.

Ao discutir o estudo de caso como estratégia de pesquisa, Yin (2001, p. 33) relata que se deve compreendê-lo como:

[...] um método que abrange tudo - com a lógica de planejamento incorporando abordagens específicas à coleta de dados e à análise de dados. Nesse sentido, o estudo de caso não é nem uma tática para a coleta de dados nem meramente uma característica do planejamento em si, mas uma estratégia de pesquisa abrangente. 
Se for comparar o estudo de caso, às outras estratégias de pesquisa, tem-se que ele "[...] representa também uma maneira de se investigar um tópico empírico seguindose um conjunto de procedimentos pré-especificados" (YIN, 2001, p. 36). Um dos principais motivos pelos quais a presente pesquisa foi assumida como o estudo de caso, assenta-se no fato de ser uma investigação que busca compreender os processos em que os jovens da EJA se apropriam dos conhecimentos para utilizá-los no mercado de trabalho.

No decorrer do estudo foram adotados os seguintes procedimentos: elaboração do projeto de pesquisa; levantamento bibliográfico para elaboração da fundamentação teórica; estudo de caso por meio de aplicação de atividades.

[...] nos estudos de caso podem incluir, e mesmo ser limitados às evidências quantitativas. $\mathrm{Na}$ verdade, o contraste entre evidências quantitativas e qualitativas não diferencia as várias estratégias de pesquisa. Observe que, como exemplos análogos, alguns experimentos têm como base evidências qualitativas, e não quantitativas. Da mesma maneira, a pesquisa histórica pode incluir enormes quantidades de evidências quantitativas (YIN, 2001, p. 33).

Para Yin (2001, p. 33), "[...] a estratégia de estudo de caso não deve ser confundida com "pesquisa qualitativa", devido algumas pesquisas qualitativas seguirem métodos etnográficos". O estudo de caso pode ser:

[...] descritivo, explanatório e exploratório, tendo suas características classificadas em: especificidades, pluralidade, contemporaneidade e análise intensiva. [...] Outra característica do estudo de caso é a variação de análise que pode vir a existir na pesquisa, sendo que o pesquisador poderá optar pela análise de um caso único ou múltiplo (YIN, 2001, p. 39). 
Considerando as teorias apresentadas, esta pesquisa é classificada como estudo de caso descritivo, com um quantitativo de 30 (trinta) estudantes da EJA, sendo 15 (quinze) do $2^{\circ}$ ano e 15 (quinze) do $3^{\circ}$ ano do Ensino Médio da EJA.

O estudo de caso é um método específico de pesquisa de campo. Os estudos de campo são investigações dos fenômenos exatamente como eles ocorrem, sem qualquer intervenção significativa do pesquisador. $O$ estudo de caso refere-se a uma análise detalhada de um caso específico, supondo que é possível o conhecimento de um fenômeno a partir do estudo minucioso de um único caso (YIN, 2001, p. 41).

A pesquisa de campo aconteceu na Escola de Ensino Fundamental e Médio Ana Lopes Balestreiro, momento em que se utilizou a dialogicidade para compreender os motivos que levam os sujeitos da EJA a retornar para a sala de aula. Para Freire (2016, p. 69), "A educação é comunicação, é diálogo, na medida em que não é a transferência de saber, mas um encontro de sujeitos interlocutores que buscam a significação dos significados".

A dialogicidade é o cerne da educação como prática da liberdade. Para Freire (2016, p. 89) o diálogo é analisado como um fenômeno humano,

[...] se nos revela como algo que já poderemos dizer ser ele mesmo: a palavra. Mas, ao encontrarmos a palavra, na análise do diálogo, como algo mais que um meio para que ele se faça, se nos impõe buscar, também seus elementos constitutivos.

Com o objetivo de garantir a qualidade e veracidade das informações, adotaram-se entrevistas para produzir os dados. Esse esboço de pesquisa focou nos momentos como um todo, procurando apresentar suas diferentes dimensões, levando em consideração o olhar da pesquisadora, da mesma forma as opiniões contraditórias que surgiram nos diversos momentos da coleta de dados, para compreender as percepções dos sujeitos pesquisados. 
A flexibilidade que caracteriza o estudo de caso permitiu diversificar os procedimentos durante a coleta de dados, pois conforme o desenrolar do estudo e a produção dos dados, adequamos os procedimentos a fim de obter um envolvimento mais aprofundado dos sujeitos da EJA e das informações coletadas.

A princípio, a pesquisa intencionava fazer questionários observando a realidade, entretanto, no decorrer da elaboração do projeto e a aproximação com o campo de pesquisa, foi considerado mais apropriado o delineamento seguindo os pressupostos do estudo de caso, referindo-se a vários sujeitos. Conforme Gil (apud CORRÊA, 2017, p. 61), no "[...] estudo de caso o fenômeno ocorre no momento da pesquisa. Esse fenômeno foi estudado como um todo, dentro do seu contexto, buscando-se profundidade na obtenção dos dados".

Os dados coletados na pesquisa são efetivamente descritivos e foram produzidos por meio da coleta delineada pelas informações, empregando as técnicas da entrevista. Este procedimento foi possível pelo fato de a pesquisadora atuar na sala de aula, espaço da mesma instituição onde os sujeitos da pesquisa permanecem, no noturno, e onde a pesquisa aconteceu. Foram momentos enriquecedores, que permitiram uma maior aproximação com o sujeito principal da pesquisa e da realidade que seria investigada por meio das entrevistas escritas.

A entrevista ocorreu de maneira informal, porém estruturada para que os sujeitos da pesquisa pudessem revelar mais sobre suas histórias de vida, trajetória escolar e as perspectivas de trabalho, seu relacionamento com os colegas e com a família, bem como com a professora. Foram relatos valiosos registrados por escrito. Este tipo de entrevista, que é menos estruturada e se delineia por meio da conversação, a pesquisadora teve como objetivo coletar mais dados que constasse se a metodologia estava favorecendo ou não a pesquisa.

As entrevistas aconteceram em sala de aula numa roda de conversa, e foram de grande avanço para a pesquisa, pois diante dessas informações, pode-se afirmar o que as revisões bibliográficas apresentaram em relação à situação na busca de vagas 
no mercado de trabalho para esses jovens da EJA. Foram recursos que serviram de aporte para a análise dos dados.

\subsection{LOCAL DA PESQUISA}

A pesquisa foi realizada na Escola Estadual de Ensino Fundamental e Médio Ana Lopes Balestreiro, que fica localizada em Flexal I, da periferia de Cariacica - ES. Trata-se de um bairro dominado pelo tráfico de drogas, e de alta periculosidade. A unidade de ensino está vinculada ao Governo do Estado do Espírito Santo. Foi criada no ano de 1982, e em 2014 inauguraram a nova sede, tendo seu espaço físico adaptado para alunos com necessidades educativas especiais, com laboratórios modernos, biblioteca com diversos títulos, além dos espaços da administração, que estão equipados com novas tecnologias.

Os bens e imóveis adquiridos estão patrimoniados pelo Governo do Estado do Espírito Santo e seus recursos financeiros são provenientes de verbas públicas estadual e/ou federal.

Os docentes são efetivos pelo Governo do Estado do Espírito Santo, além desses, os contratados em Designação Temporária. Todos com qualificação profissional nas respectivas áreas.

A filosofia educacional da unidade de ensino está centrada no resgate dos valores fundamentais, desenvolvendo critérios humanísticos que respeitam a dignidade dos jovens e, consequentemente, são preparados para o exercício da cidadania e do trabalho.

Mediante a localização da unidade de ensino se localizar na periferia do município de Cariacica - ES com grande incidência de casos de violência, muitos alunos que a frequentam são vítimas, ou mesmo agressores, no mundo de onde são oriundos. Diante desta realidade, a escola dirige-se à formação de valores, no sentido de preencher as lacunas na vida diária destes alunos. 
A escola tem como missão garantir a todos os estudantes da região onde está inserida uma educação pública de qualidade, capaz de promover transformação social e desenvolvimento local equilibrado.

A visão da escola é ser reconhecida pela melhoria dos indicadores de acesso e qualidade do ensino-aprendizagem como resultado de uma gestão pedagógica e administrativa transformadora, baseada nos princípios e competências do século XXI, consolidando-se como escola referência na oferta de educação básica na região onde se insere.

Sua clientela é caracterizada pela diversidade de raça, perfil sócio econômico, cultural, etc., uma vez que a unidade atende alunos advindos de comunidade carente.

Para atender ao Ensino Médio no turno noturno, esta diversidade aumenta, visto que nesse horário predominam alunos trabalhadores. Eles trabalham durante $\mathrm{o}$ dia $\mathrm{e}$ estudam a noite. A escola está sempre atenta a esta característica e busca encontrar formas de estudo e avaliações para que não sofram prejuízos acadêmicos.

\subsection{SUJEITOS DA PESQUISA}

Os sujeitos da pesquisa são 30 (trinta) jovens e adultos estudantes da EJA, sendo 15 (quinze) do $2^{\circ}$ ano e 15 (quinze) do $3^{\circ}$ ano. São jovens advindos da periferia, que residem em bairros de área de risco e alta periculosidade, onde o tráfico de drogas e automóveis é intenso, convivem diariamente com a violência sendo vítimas ou agressores do mundo em que estão inseridos. São bairros formados por meio da invasão, sendo, muitos, nascidos na Bahia, Rio de Janeiro, Ceará e Pernambuco. A clientela atendida é proveniente de bairros sem infraestrutura, ruas ainda para asfaltar, sem rede de esgoto, sendo que a maioria faz fossa ou joga na rua. Vive em extrema pobreza. Os moradores possuem culturas e tradições diferentes dos capixabas, tendo um conceito de família diferente das tradicionais. São pessoas carentes de pai e mãe que abandonaram tudo e vieram tentar a sorte, mas, infelizmente, falta a escolarização e a qualificação, vivendo dos subempregos, o que os leva a diferentes tipos de atitudes ilegais e marginais, pois, assim, o dinheiro chega mais fácil em suas 
mãos. Entretanto, nem todos têm esse pensamento, há os que querem vencer com honestidade e de forma correta. Passam fome e a única refeição é a que a escola oferece à noite, no horário de intervalo das aulas.

Muitos são usuários de álcool e de drogas (basicamente, maconha e cocaína) e, além disso, traficam-nas. Em alguns momentos, aparecem na escola sob o efeito de alucinógenos ou alcoolizados e nada produzem. Vão apenas para fazer a refeição e para vender as drogas, ou negociarem com os donos dos postos de venda.

A maioria dos jovens e adultos estão cursando o Ensino Fundamental e Médio da Educação de Jovens e Adultos devido a uma série de situações, como: repetência, evasão, abandono e desemprego. Boa parte destes estão em busca de um lugar no mercado de trabalho e não conseguem a oportunidade por falta de qualificação, sendo reprovados na primeira entrevista ou até mesmo nem sendo convocados para fazêla.

Dos 30 jovens e adultos investigados, 50\% são homens e 50\% são mulheres, sendo $60 \%$ casados, $60 \%$ são mantenedores de lar e $80 \%$ tiveram que sair da escola pela necessidade de trabalhar, $60 \%$ residem no bairro onde moram e trabalham, $20 \%$ necessitam de transporte coletivo para trabalhar e estudar, e 20\% vão a pé ou de bicicleta para a escola. Entretanto, o Estado oferta um transporte escolar (ônibus) para levar e buscar àqueles que moram muito afastados e não trabalham.

Mediante tal realidade, foi elaborado um roteiro de perguntas para serem feitas por meio de entrevistas e observações com os alunos. As entrevistas foram individuais, para que pudesse fazer os registros e elaborar a descrição e análise dos dados coletados.

As maiorias desses jovens e adultos que retornam para a escola vão com o objetivo de ter uma qualificação, por perceberem a necessidade desta para conseguirem uma chance no mercado de trabalho, fato que ficou explícito na pesquisa.

Os sujeitos pesquisados revelaram suas trajetórias, suas conquistas, seus percalços. São cidadãos que idealizam e, apesar das dificuldades enfrentadas, foram fortes e se 
mostraram com garra para ultrapassar a situação de pobreza. Mas é preciso que o Estado faça sua parte, devolvendo a dignidade que a escassez de condições materiais, impostas durante a vida, Ihes retirou.

\section{PRODUTO EDUCACIONAL}

O produto educacional pode ser um aplicativo, um texto para o professor, um vídeo, uma estratégia didática, um guia, uma revista digital, um e-book, o uso do computador, do celular, etc., em sala de aula para ensinar. As opções são muitas, o importante é inovar, gerar um produto, usá-lo em situação real de sala de aula e relatar o que aconteceu.

Obviamente, que é necessário planejar a implementação do produto e registrar o que acontece. Mas não se trata de revisão da literatura, fundamentação teórica, metodologia de pesquisa, tal como se espera de uma dissertação acadêmica ou de uma tese de doutorado.

O Produto Educacional foi um Guia de Orientações que não foi fácil de ser construído. Ficamos muito tempo para chegarmos à conclusão deste. Muita ausência dos alunos fez com que ao retornarem fosse necessário dar continuidade ao conteúdo de sala para não perderem as oportunidades, mas com todas as dificuldades conseguiram terminar.

O Guia de Orientações traz uma série de comportamentos e atitudes necessárias para a preparação dos sujeitos antes e durante as entrevistas que farão para conquistar uma vaga no mercado de trabalho. O guia contém ilustrações feitas pelos alunos, orientações de como se vestir, se apresentar durante a entrevista, o comportamento e uma lista de profissões que poderiam almejar. Tem depoimentos de três alunos relatando como conseguiram encontrar o emprego, aborda também as competências emocionais. Foi realizado pelos alunos. Em cada detalhe, em cada item, nos desenhos, nas ilustrações coletadas pela internet, todo o processo foi feito no laboratório de informática e nos momentos de sala de aula. Foram pesquisas que os grupos iam fazendo e trazendo para a sala e, assim surgiu o guia como um Produto 
Educacional que, com certeza, irá auxiliá-los em suas jornadas na busca de um emprego.

\section{CONSIDERAÇÕES FINAIS}

Diante do que foi apresentado, é possível rever alguns aspectos da Educação de Jovens e Adultos, tais como o histórico da EJA e sua evolução, a juventude atual, além de constatar que essa modalidade é uma educação possível. Ao longo dos anos, o avanço da tecnologia e da economia tem feito com que as pessoas sintam necessidade de retornar à sala de aula para aprimorar seus conhecimentos ou conseguir um diploma atestando uma escolarização mais elevada.

Hoje, a EJA é uma modalidade de ensino que pode transformar a vida de um indivíduo. E o fato de o educando atrasar para o ingresso na educação formal não é motivo para o não ingresso, mesmo que tardiamente, uma vez que ela é um processo contínuo.

A inserção vivenciada nas situações diárias do jovem e do adulto, no contexto social e profissional, admite o começo de uma relação dialógica com as novas informações disponibilizadas pela educação escolar. Existem diferenças de entendimento e de registro entre as pessoas sem escolaridade, e as que podem frequentar a escola. Quando os alunos veem seus conhecimentos anteriores à escolarização, ou antes, a ela, uma ponte se cria para que a aprendizagem se torne cada vez mais significativa. Por outro lado, a escola deve zelar por essa relação, reconhecendo as habilidades cognitivas de seus alunos e proporcionando momentos de atuação sobre a construção do próprio conhecimento.

Para tanto, a educação escolar pode intervir na transformação futura do mundo, ressignificando por meio da reflexão informada sobre os valores da ética e do convívio social harmonioso. E os alunos, quando bem informados, podem realizar as suas melhores escolhas.

Com o problema de pesquisa indagando como se caracterizam as trajetórias percorridas pelos jovens e adultos da EJA, para encontrar uma oportunidade no 
mercado de trabalho cursando apenas o Ensino Médio, buscou-se compreender a importância da preparação dos estudantes dessa modalidade de ensino.

$\mathrm{Na}$ investigação sobre as trajetórias percorridas com os desafios e as dificuldades para buscar uma oportunidade no mercado de trabalho e a partir dos estudos decidimos elaborar um guia para que todos tivessem acesso às informações, de grande valia, para o momento tão esperado, que é a entrevista de um emprego.

Além disso, percebeu-se que os jovens que frequentam o ensino da EJA já não estão mais tão preocupados em adquirir novos conhecimentos, mas sim em finalizar o Ensino Médio o mais rápido possível para poder competir no mercado de trabalho. Alguns buscam a qualificação, por já entenderem que sem uma formação específica terão muitas dificuldades para se colocarem no mercado de trabalho, outros não estão preocupados em ter um curso, mas em finalizar o Ensino Médio e não mais frequentar da escola.

\section{REFERÊNCIAS}

BRASIL. INEP MEC. Resultados finais do Censo Escolar de 2018. Disponível em: $<$ http://portal.inep.gov.br/web/guest/resultados-e-resumos>. Acesso em: 03 ago. 2019.

Lei de Diretrizes e Bases da Educação Nacional - LDBEN n. 9.394/96. Ministério da Educação e Cultura. Secretaria de Educação. Brasília: MEC/SEESP, 2004

. Ministério da Educação e Cultura. Secretaria de Educação Continuada, Alfabetização e Diversidade. Trabalhando com a Educação de Jovens e Adultos. Alunas e alunos da EJA. Brasília, 2006.

. Secretaria Especial dos Direitos Humanos. Organização das Nações Unidas (ONU). Declaração Universal dos Direitos Humanos. Adotada e proclamada pela resolução 217 A (III) da Assembleia Geral das Nações Unidas em 10 de dezembro de 
1948. Disponível em: <http://www.presidencia.gov.br/sedh/>. Acesso em: 02 mai. 2019.

CORRÊA, Gisély de Abrêu. Apropriação do conceito de sistema de numeração decimal por uma criança com Síndrome de Down na perspectiva da teoria da formação planejada das ações mentais. Dissertação (Mestrado em Educação em Ciências e Matemática). Instituto Federal do Espírito Santo, Vitória, ES: 2017, 146 f.

CUNHA, Conceição Maria da. Introdução - discutindo conceitos básicos. In: SEEDMEC Salto para o futuro - Educação de jovens e adultos. Brasília, 1999.

DICK, Hilario. Silêncios e barulhos juvenis latino-americanos. São Paulo: Unisinos, 2016.

FREIRE, Paulo. Educação e mudança. 36. ed. Rio de Janeiro: Paz e Terra, 2016.

Pedagogia da Autonomia: saberes necessários à prática educativa. 43 ed. Rio de Janeiro: Paz e Terra, 2011.

Pedagogia do Oprimido. 50. ed. Rio de Janeiro: Paz e Terra, 2019.

GUIMARÃES, Gilselene Garcia. GRINSPUN, Mírian Paura Sabrosa Zippin. Revisitando as origens do termo juventude: a diversidade que caracteriza a identidade. Disponivel em: <http://www.anped.org.br/sites/default/files/gt20-4136int.pdf>. Acesso em: 09 ago. 2019.

HALL, Stuart. A identidade cultural na pós-modernidade. 7. ed., Rio de Janeiro: DP\&A, 2014.

LAMEIRAS, Maria Andrea Parente (et. al.). Mercado de Trabalho. Carta de Conjuntura. IPEA, n. 43. Segundo trimestre de 2019. Disponível em: $<$ http://www.ipea.gov.br/portal/images/stories/PDFs/conjuntura/190618_cc_43_merc ado_de_trabalho.pdf>. Acesso em: 03 set. 2019. 
NOVAES, Regina Célia Reyes (Orgs.). Política Nacional de Juventude: diretrizes e perspectivas. São Paulo: Conselho Nacional de Juventude, Fundação Friedrich Ebert, 2019.

PATTO, Maria Helena de Souza. A produção do fracasso escolar: histórias de submissão e rebeldia. São Paulo: Editora Intermeios, 2015.

PORCARO, Rosa Cristina. A história da educação de jovens e adultos no Brasil. Disponível em <http://www.dpe.ufv.br/nead/docs/ejaBrasil.doc> Acesso em 01 jun. 2019.

RAGGI, Désirée Gonçalves et. al. As percepções dos professores da educação profissional que atuam no Proeja: uma abordagem reflexiva para além da formação técnica. In: Revista Expressão Católica, v.2, n.1, Jan./Jun. 2013.

ROCHA, Sonia. A inserção dos jovens no mercado de trabalho. Cad. $\mathrm{CRH}, \mathrm{v} .21$, n. 54, Salvador, Set./Dez. 2008. Disponível em: <http://www.scielo.br/scielo.php?script=sci_arttext\&pid=S010349792008000300009>. Acesso em: 05 ago. 2019.

SOARES, Leôncio José Gomes. A educação de jovens e adultos: momentos históricos e desafios atuais. Revista Presença Pedagógica, v. 2, n. 11, Dimensão, set./out. 1996.

YIN, Robert K. Estudo de caso: Planejamento e Métodos. 2. Ed. Porto Alegre: Bookman, 2001.

\section{APÊNDICE - REFERÊNCIAS DE NOTA DE RODAPÉ}

3. UNESCO - Organização das Nações Unidas para a Educação, Ciência e Cultura

4. ONU - Organização das Nações Unidas

5. SEA - Serviço de Educação de Adultos 
6. MEC - Ministério da Educação e Cultura

7. MOBRAL - Movimento Brasileiro de Alfabetização

8. USAID - United States Agenci for International Development (Agência dos Estados Unidos para o Desenvolvimento Internacional)

9. ENEJA - Encontro Nacional da Educação de Jovens e Adultos

10. CONFINTEA - Conferência Internacional sobre Educação de Jovens e Adultos

11. PNJ - Política Nacional de Juventude

Enviado: Abril, 2020.

Aprovado: Abril, 2020. 